Philosophia Mathematica (III) 00 (2011), 1-24. doi:10.1093/phimat/nkr005

\title{
The Hardness of the Iconic Must: Can Peirce's Existential Graphs Assist Modal Epistemology ${ }^{\dagger}$
}

\author{
CATHerine LeGG*
}

\begin{abstract}
Charles Peirce's diagrammatic logic - the Existential Graphs - is presented as a tool for illuminating how we know necessity, in answer to Benacerraf's famous challenge that most 'semantics for mathematics' do not 'fit an acceptable epistemology'. It is suggested that necessary reasoning is in essence a recognition that a certain structure has the particular structure that it has. This means that, contra Hume and his contemporary heirs, necessity is observable. One just needs to pay attention, not merely to individual things but to how those things are related in larger structures, certain aspects of which relations force certain other aspects to be a certain way.
\end{abstract}

\section{Introduction}

I wish to use the role of diagrams in mathematical and logical reasoning to inform a broader inquiry into modal epistemology $y^{1}$ - specifically examining how we come to know necessary truth. Although mathematics is not the only science which involves necessary truth, it seems to concentrate on it to an extent that has even been considered defining. Thus for instance Benjamin Peirce (father of Charles) began his landmark Linear Associative Algebra by claiming that mathematics is 'the science that draws necessary conclusions' [Peirce, 1870, p. 1]. I wish to defend the following hypothesis:

Key Hypothesis: Structural articulation is the source of all knowledge of necessity. Necessary reasoning is in essence just a recognition that a certain structure has the particular structure that it in fact has.

$\dagger$ For discussions which greatly improved this paper I am indebted to the participants of the 'Pictures and Proofs in Mathematics' stream, Australasian Association of Philosophy Conference (NZ Division), Massey University, December 2009, as well as subsequent feedback from Philip Catton, Nathan Houser, Clemency Montelle, Charles Seibert, Neil Sinhababu, Koji Tanaka, and Zach Weber. Thanks are due also to two anonymous referees for some very well-informed and perceptive suggestions.

* Philosophy Programme, University of Waikato, Hamilton, New Zealand. clegg@waikato.ac.nz

1 To clarify, by 'modal epistemology' I do not mean theories which explicate all knowledge as modal, such as epistemic modal logics, e.g., [Meyer, 2003]. Rather I mean how we come to know modal claims. 
If established, this claim will be valuable in dispelling a bafflement often expressed by philosophers concerning the objects and ground of our knowledge of necessity. Though this bafflement supposedly springs from 'naturalism', I hope to show that it leads to an inability to see certain ubiquitous phenomena which is in essence unscientific. The claim as it stands is ambitious and possibly controversial. For instance, the use of the words 'in fact' might suggest that the hypothesis seeks to reduce truth about all possible situations to truth in the actual world. This is not my aim. The glory and mystery of necessary reasoning is that the structures I will discuss, while experienceable in the actual world, somehow manage to gain transworld significance, ${ }^{2}$ as they must if we are to reason by means of them. The 'in fact' is merely meant to invoke rhetorically a certain moment of recognition - in that sense one might say that it is an epistemic rather than a metaphysical 'in fact'. To be more precise, I mean that what is recognized has no content over and above what is represented by the structure that is already present, but nevertheless constitutes some kind of new insight. But more on this below.

Consider something we arguably know, which is necessarily true:

M1: IF three odd numbers are added together THEN the result will also be an odd number.

How do we manage to know M1? Here I am seeking what might be termed Good Old-Fashioned Epistemology. A classic example of this might be Hume's skeptical examination of the idea of substance in Treatise (I, vi). Here Hume claims that every idea must derive either from sensation or reflection; the idea of substance cannot derive from sensation as it is not seen, heard, smelt or tasted ... and cannot derive from reflection as, 'the impressions of reflection resolve themselves into our passions and emotions: none of which can possibly represent a substance.' Therefore, he concludes, we have no knowledge of substance.

Can such a structured and systematic story be told about our knowledge of M1? Such a project has been traditionally viewed as subject to a major challenge. A classic Hume-style epistemology gains much of its explanatory power from viewing us as natural objects causally embedded in the world, and our interaction with worldly objects forms a large part of the story about how we know them. But in the case of mathematics, what

2 This use of the phrase 'trans-world significance' should not be interpreted as necessarily implying a commitment to analyzing modality by means of currently popular David Lewis-style discrete and/or concrete possible worlds. It is merely meant to convey a more broadly conceived modal realism according to which actuality does not exhaust all there 'is'. Peirce although a resolute realist of this broader kind, has a different modal semantics, as we shall see. I am grateful to Zach Weber for raising these issues. 
objects might we be said to interact with so that we can reconstruct how our knowledge of them might be justified? True mathematical statements such as M1 if taken at face value seem to require commitment to a numeric Platonism. And Platonism has been rejected as embracing an untenable epistemological mystery. For example Benacerraf argues that most 'semantics for mathematics' do not 'fit an acceptable epistemology', since the former:

... will depict truth conditions in terms of conditions on objects whose nature, as normally conceived, places them beyond the reach of the better understood means of human cognition (e.g., sense perception and the like). [Benacerraf, 1973, p. 667]

He further explicates 'acceptable epistemology' by stating:

For Hermione to know that the black object she is holding is a truffle ... that the black object she is holding is a truffle must figure in a suitable way in a causal explanation of her belief that the black object she is holding is a truffle. [Benacerraf, 1973, p. 671]

The epistemology of modality has been relatively neglected in mainstream analytic philosophy (even after considerable attention began to be devoted to the metaphysics of modality through the 1970s and 80s), and this arguably has much to do with Hume, ${ }^{3}$ who is discussed further in the next section.

\section{Hume and his Heirs: The Contingency of Experience}

For Hume and empiricism downstream from him, to put it crudely, ordinary middle-sized objects are observable, necessity is not.

I consider, in what objects necessity is commonly suppos'd to lie; and finding that it is always ascrib'd to causes and effects, I turn my eye to two objects suppos'd to be plac'd in that relation.... I immediately perceive, that they are contiguous in time and place, and that the object we call cause precedes the other we call effect. In no one instance can I go any farther, nor is it possible for me to discover any third relation betwixt these objects. [Treatise, III, xiv]

Such necessary truths as there are, Hume claims, merely consist in relations between ideas. Apart from trivial definitional truths (e.g., 'All bachelors are unmarried') this category covers only mathematics. And in fact

\footnotetext{
${ }^{3}$ Also worthy of note here of course is Quine, e.g., [1947; 1953], who however continues much of Hume's empiricist tradition.
} 
even here, in remarks little attended to today, the early Hume claims skepticism:

\begin{abstract}
... the ideas which are most essential to geometry, viz. those of equality and inequality, of a right line and a plain surface, are far from being exact and determinate, according to our common method of conceiving them. Not only we are incapable of telling, if the case be in any degree doubtful, when such particular figures are equal ... but we can form no idea of that proportion, or of these figures, which is firm and invariable. Our appeal is still to the weak and fallible judgment, which we make from the appearance of the objects, and correct by a compass or common measure; and if we join the supposition of any farther correction, 'tis of such-a-one as is either useless or imaginary ... As the ultimate standard of these figures is deriv'd from nothing but the senses and imagination, 'tis absurd to talk of any perfection beyond what these faculties can judge of .... [Treatise, II, iv]
\end{abstract}

Here Hume seems almost to suggest that mathematicians are deluding themselves in pretending to pursue an exact science. ${ }^{4} \mathrm{He}$ seems to deny the existence of any ideal objects, or any real exactitude in mathematical properties and relations, claiming that to purport otherwise is 'either useless or imaginary'. Although this sort of denouncement has been expunged from the Enquiry, it is worth pausing to note the sweeping purity of the young Hume's empiricist vision. Of course, by this full-fledged assault on our knowledge of the necessary, Hume takes himself to abolish much worthless metaphysics, a result traditionally much admired. However it is also worth noting how much of this exhilarating abolition relies on an epistemological methodology which is unquestioningly atomist. It is logically atomist in that all our knowledge is built up (in principle) from impressions and the ideas they generate. It also may be described as 'socially' atomist in the sense of epistemologically individualist — if one finite mind cannot tell (merely by using its senses) whether two particular figures are equal, then there is no answer as to whether they are, Hume assumes here. We will have cause to examine the first methodological constraint in this paper. (The second would be an interesting topic for a future study.) A summary of Hume's epistemology of necessity that has been influential through recent philosophical history - for instance in Kant's response to Hume - albeit somewhat sloganistic, is that all necessity is analytic.

${ }^{4}$ One might counter-claim that Hume hedges his skepticism about the exactitude of mathematics by including the qualifier, 'according to our common method of conceiving them'. But this suggestion is undermined by the seemingly absolute closing claim that, '... the ultimate standard of these figures is deriv'd from nothing but the senses and imagination'. 


\title{
3. Metaphysical Necessity Rides Again
}

As noted, in many ways analytic philosophy in its approach to modality is still outgrowing the legacy of Hume. Thus Crispin Wright writes, citing Simon Blackburn:

\begin{abstract}
'We do not understand our own must-detecting faculty. ${ }^{5}$ Not only are we aware of no bodily mechanism attuned to reality's modal aspects, it is unclear how such a mechanism could work even in principle. [Wright, 1986, pp. 206-207]
\end{abstract}

However in the twentieth century it began to appear that in fact not all necessity can be reduced to what is 'true by definition'; rather, some is discovered. The now hackneyed example is 'Water is $\mathrm{H}_{2} \mathrm{O}$ '. Influential figures such as Kripke and (early mid-) Putnam drew on such examples to announce a new category of a posteriori necessity (a.k.a. 'metaphysical necessity'). It is worth noting that this form of necessity is described as a posteriori as it was scientists who discovered the chemical formula of water. However strictly speaking the scientists did not discover that the statement is necessarily true. This aspect of the claim is attributed by philosophers, initially by consulting 'intuitions' about an imaginary planet known as Twin Earth.

It is worth briefly outlining the background to these developments and the understandings of necessity embodied therein, and comparing them with Peirce's understanding of necessity. An important bridge between Hume and contemporary analytic treatments of modality was the 'logical empiricism' of Carnap. In his 1947 Meaning and Necessity, Carnap explicated necessity by defining a concept of $L$-truth (logical truth) which consists in those statements which are true in all state descriptions. This is to be contrasted with $C$-truth (contingent truth) which is true only in some state descriptions. A state-description is a maximal collection of atomic sentences for a given language. For every predicate $P$ of that language and every combination of singular terms $(a, b, \ldots)$ equal to the number of its argument-places, the state description contains either $P a b[\ldots]$ or $\sim P a b[\ldots]$. (The conception owes much to Wittgenstein's Tractatus). This understanding of necessity is still Humean insofar as Carnap claims that L-truth 'follows from the semantical rules alone' [Carnap, 1947, p. 1] or in other words, is analytically true. ${ }^{6}$

5 Here Wright cites [Blackburn, 1986, p. 119].

${ }^{6}$ One might argue that L-truth should not be identified with analyticity for — as Quine pointed out - for a language with 'extra-logical synonym-pairs' such as 'bachelor' and 'unmarried man' the state-description method will assign independent truth-values to statements such as 'Fred is a bachelor', and 'Fred is an unmarried man'. However Carnap did describe the state-description method as 'an explicatum for what Leibniz called necessary truth and Kant analytic truth' [Carnap, 1947, p. 8]. 
Shortly afterwards however key developments in formal logic took place. Saul Kripke [1959] proved completeness for a model theory for modal logic which replaced state descriptions with frames. Each Kripke frame consists in a set of possible worlds $W$ and a binary accessibility relation $R$ over them. Mathematical features of possible $R \mathrm{~s}$ such as symmetry, reflexivity, and transitivity neatly explicate different modal systems such as S4 and S5. Different accessibility relations also allow an elegant division of modality into different 'flavors'. For instance physical may be distinguished from logical necessity by defining a 'nomological accessibility' whereby all worlds with the same physical laws as a given world are nomologically accessible to it, then claiming that a statement is logically necessary if true in all possible worlds, physically necessary if true in all nomologically accessible worlds.

Crucially, entailment could then be given a new 'semantic' interpretation according to which $A$ entails $B$ iff in all worlds in which $A$ is true, $B$ is true also. This decoupled entailment from provability in principle, allowing a greater externalism into modal epistemology. One could no longer assume with Carnap that necessary truth 'followed from the semantical rules alone', at least as 'semantical rules' had previously been understood. David Lewis took advantage of this new externalism to give the Kripkean logical apparatus what might be referred to as an extreme metaphysical realist interpretation, according to which other possible worlds exist in just as concrete a form as 'ours', and actuality is merely indexical [Lewis, 1986]. According to this brand of modal realism our irremediable lack of certain knowledge regarding the contents of these entirely spatiotemporally disconnected worlds is to be expected and appreciated as a sign of mind-independence in the modal subject matter, rather than deprecated.

For Peirce by contrast modal metaphysics and epistemology were never sundered in this extreme form, although it is important to note that his view developed through his career. Robert Lane [2007] provides a useful summary of Peirce's evolving thinking on necessity. He notes following [Morgan, 1979] ${ }^{7}$ that Peirce began with an information-relative account of necessity, according to which a statement is necessary if known to be true (and possible if not known not to be true) given a certain state of information. This also allows the distinction between modal flavors alluded to above, insofar as one can restrict states of information to laws of nature for physical modality, current knowledge for epistemic modality, and so on [Lane, 2007, pp. 555-556]. Peirce gradually became dissatisfied with the information-relative account, however, and his reason for this is interesting in the current context. He writes:

\footnotetext{
${ }^{7}$ See also [Pietarinen, 2006].
} 
It is not that certain things are possible because they are not known not to be true, but that they are not known not to be true because they are, more or less clearly, seen to be possible. [Peirce, Collected Papers, 6.367, 1902] $]^{8}$

His thinking therefore evolved towards an ideal-world account, according to which we discern modal facts less via inference from a given state of information than via some kind of direct perceptual experience of a 'world of ideas' which is 'but a fragment of the ideal world' [Lane, 2007, p. 563]. Peirce writes that with respect to this ideal world we are "virtually omniscient'. He envisaged that by inspecting it one might be able to determine that a given proposition is impossible although the laws of logic do not show that the proposition contains any contradiction. ${ }^{9}$

\section{Imagining vs Imaging: Contemporary Analytic Modal Epistemology}

To return to contemporary analytic modal epistemology, then, at some point intuitions concerning the necessary truth of 'Water is $\mathrm{H}_{2} \mathrm{O}$ ' came to appear rather under-theorized. Philosophers do not always agree with respect to modal intuitions, particularly where the imagined scenarios are quite baroque and odd. Some need was felt for a more principled modal epistemology. A pioneer was Stephen Yablo, who drew self-consciously on Hume, framing a theory of our knowledge of possibility in terms of conceivability, suggesting that in fact this is the only viable route to a modal epistemology ${ }^{10}$ His key claim is that, 'A proposition $p$ is conceivable iff one can imagine a world that one takes to verify $p$ ' [Yablo, 1993, p. 29]. Then a proposition is possibly true if it is conceivable, and necessarily true if it is not conceivable that it not be true.

What is it to conceive something? Although Yablo pays close attention to conceivability's functional role, or results, distinguishing between conceivability $b$ ('the believability of $p$ is possible', p. 20), conceivability ${ }_{\mathrm{ijb}}$ ('imagining acquiring evidence that justifies you in believing that $p$ ', p. 22), conceivability ${ }_{\text {itb }}$ ('the imaginability of veridically or truly believing that $p^{\prime}$, p. 22$)$, conceivability ep $^{(} \ldots$ one can imagine .... believing something true with one's actual $p$-thought', p. 24), he says little

${ }^{8}$ Peirce's Collected Papers [1931-1958] will be referred to as $C P$ with section, page, and date of original publication appended.

${ }^{9}$ What Peirce particularly had in mind was a certain proposition in set theory which space does not permit discussion of here. For details see [Lane, 2007] and [Morgan, 1979, pp. 72-73].

10 'If there is a seriously alternative basis for possibility theses, philosophers have not discovered it'. [Yablo, 1993, p. 2] 
about the epistemic mechanism(s) which might produce such results. He does note that the imagination will be deeply involved, but suggests that imagining is to be distinguished from imaging:

Some philosophers use 'imagine' so that imagining a thing is imaging it, that is, conjuring up an appropriate sensory presentation. I do not require a sensory-like image for imagining, and certainly not a distinct such image for distinct imaginings. (Compare Descartes on the unimaginability of chilliagons ... .) [Yablo, 1993, p. 27, fn. 55]

This led Peter Van Inwagen to argue that although Yablo's account is probably pretty accurate with respect to how we do in fact get modal knowledge, it is question-begging for justifying a large number of modal claims beyond well-tried everyday situations - particularly modal claims made by philosophers. He therefore embraces a modal skepticism, of an academic rather than Pyrrhonian variety [Van Inwagen, 1998, p. 69]. In support of his position he proffers the example of whether there might be transparent iron. He argues that one cannot know whether one can conceive transparent iron unless one already knows whether it is possible. Consider for instance a scenario where a scientist is pointing to a transparent object and saying, 'I am sure that this is iron!' This could be a scene which depicts the existence of transparent iron, but it could equally be a scene which depicts other possibilities:

This sort of effort of imagination will ... show that a certain proposition has the modal status 'possible,' but the proposition will be a disjunctive one. Here are some of its disjuncts:

- Transparent iron exists

- The scientific community has somehow been deceived into thinking that transparent iron exists

- A crackpot physicist who thinks he has created transparent iron is the butt of a cruel and very elaborate practical joke ... [Van Inwagen, 1998, p. 79]

This issue of when and how a depiction might guarantee a given epistemic result is most intriguing. Van Inwagen does suggest that if one specified enough structural detail one might describe a scenario which could only correspond to the possibility of transparent iron, but essentially leaves this question hanging, since:

... although, if we wished to establish the possibility of transparent iron, we should have to operate at the same level of imagined detail as condensed-matter physicists, we might not be subject to the same constraints as they [Van Inwagen, 1998, p. 80]

— these constraints being the actual laws of nature. 
Chalmers follows Yablo with some extra 'bells and whistles'. He distinguishes between negative conceivability (' $S$ is not ruled out' [Chalmers, 2002, p. 149]) and positive conceivability ('one can form some sort of positive conception of a situation in which $S$ is the case' [Chalmers, 2002, p. 150]), favoring the latter as his guide to possibility. He claims:

$S$ is positively conceivable when one can coherently modally imagine a situation that verifies $S$. A situation is coherently imagined when it is possible to fill in arbitrary details in the imagined situation such that no contradiction reveals itself. [Chalmers, 2002, p. 151].

So far this seems rather reminiscent of Peirce's ideal-world account of modality. But Chalmers also seems to make an effort to avoid understanding imagining as 'imaging' insofar as he distinguishes between perceptual and modal imagination and notes that although imagining that $P$ is more than just 'entertaining or supposing that $P$ ', in that it has some kind of 'mediated objectual character' (p. 150), '[t]his objectual character is also present in cases of imagination that are not grounded in imagery' (for instance imagining molecules of $\mathrm{H}_{2} \mathrm{O}$ ). He also claims that 'one can imagine pairs of situations that are perceptually indistinguishable', for instance, 'the situations postulated by two scientific hypotheses that make the same empirical predictions'. In an important sense of 'perceptual' my hypothesis is committed to this claim's being false.

In order to argue for my key hypothesis I offer not so much a deductive proof as a theoretical framework which I will suggest renders key issues properly perspicuous. To this end, in the next section I outline Peirce's concept of the iconic sign (which is to be contrasted with indices and symbols), which enables a semiotic argument, drawing on the functional role of different kinds of signs. Then in §6 I offer a further argument for what I call 'the hardness of the iconic must' which is in essence phenomenological. In \$7 I inquire into the source or ground of this remarkable feature of our mental landscape, then in $\$ 8$ present Peirce's existential graphs as a key technology for revealing and exploring it. By this means I derive criteria for distinguishing exactly which aspects of a formalism represent necessary truth. Having argued that iconic signs are the only, or 'essential', means of epistemic access to such necessity, in \$9 I give a final answer to Humean modal epistemology.

\section{Icon, Index, Symbol}

For Peirce every sign is characterized by a triadic structure which holds irreducibly between some signifying item ('representamen'), an object, 
and an interpretation. ${ }^{11}$ Symbols (such as the word 'cat') represent their object via some convention which must be learned. This is the kind of sign philosophers, who are traditionally very word-oriented, have felt most comfortable exploring. However through the 1960s and 70s a recognition was forced into mainstream philosophy, e.g., [Perry, 1979], that language also includes signs which pick out their object via some direct unmediated relationship (for instance a pointing finger, the word 'I'). These are known as 'indexicals' - Peirce called them indices.

But Peirce considered a third type of sign equally distinct and important. These are icons, which pick out their object by possessing the quality signified (e.g., [Peirce, CP, 2.304]). Another of Peirce's definitions of the icon is that its parts should be related in the same way that the objects represented by those parts are themselves related. [Peirce, $C P$, $3.363 ; 3.641]$ Thus icons are the only signs whose signification (can) have internal structure. ${ }^{12}$ For an index is just a pointer, and although the convention by means of which the symbol symbolizes what it does may have structure, that structure will be external to the signification, in the following sense. One might for example analyze the convention which connects the word 'jade' with particular sets of stones in particular contexts, distinguishing between, for instance, a Chinese convention, a European convention, and a New Zealand convention for defining jade. However none of these 'convention-parts' are related in the same way as the parts of the sign 'jade' - namely the letters J, A, D, and E - are related.

Most real-world signs are a mixture of these three sign-types (for instance ' $I$ ' is index insofar as it indicates its speaker, and symbol insofar as we have to learn that it is the word ' $\mathrm{I}$ ' that plays this role). A further three-way distinction holds between (roughly speaking) terms, propositions and arguments, which are functionally defined as follows: 13

\begin{tabular}{|l|c|c|c|}
\hline & Term & Proposition & Argument \\
\hline Determines information to be conveyed & No & Yes & Yes \\
Determines inferences to be drawn & No & No & Yes \\
\hline
\end{tabular}

As examples of these three, consider as Term: '- is on the mat', as Proposition: 'The cat is on the mat', and as Argument: 'The cat is on the mat. If the cat is on the mat, then the dog is not in the room. Therefore the dog is not in the room.'

11 This interpretation does not have to be actual, it can be potential, therein lying a great deal of Peirce's realism.

12 The 'can' is added as the icon may not have internal structure insofar as the 'quality' shared by representamen and object might merely consist in some simple quale (a color for instance). However these are arguably degenerate cases.

13 See, for instance, [Peirce, $C P, 2.95 ; 4.354 ; 4.438]$. 
Mathematical diagrams, insofar as they depict mathematical structure, are iconic signs. Since Peirce claimed that all signs have objects, one might wonder, what is the object of, say, a diagram in geometry? Once again, Benacerraf's worries about 'semantic' commitment loom. However these may be addressed via Peirce's nuanced analysis of signification. As the table above reminds us, a term is not yet a proposition. Although icons have objects, this does not mean that by using, say, a diagram of a triangle, one is thereby making a truth-claim about, for instance, the existence of a triangle (in whatever way triangles might exist). In fact one distinguishing mark of the icon compared to the other two sign-types, Peirce claims, is precisely that it signifies what it does whether or not its object exists:

An icon is a representamen which fulfils the function of a representamen by virtue of a character which it possesses in itself, and would possess just the same though its object did not exist. Thus, the statue of a centaur is not, it is true, a representamen [of a centaur] if there be no such thing as a centaur. Still, if it represents a centaur, it is by virtue of its shape; and this shape it will have, just as much, whether there be a centaur or not. [Peirce, $C P, 5.73,1903]$

To interpret a statue of a centaur as a claim that centaurs exist is to add some further significance to it. This further significance can only derive from the application of some convention that would have to be learned. (Consider that one would have to teach a child to regard the statue in such a way.) Peirce generalized from such examples to claim that only when icons (and indices for that matter) are embedded in symbols does one get a true or false claim. ${ }^{14}$ What would one be doing with signs if not making assertoric claims? One might for instance be discerning the necessary consequences of a hypothesis, and Peirce suggests mathematics gives a fine illustration of exactly this:

A geometrical diagram is a good example of an icon. A pure icon can convey no positive or factual information; for it affords no assurance that there is any such thing in nature. But it is of the utmost value for enabling its interpreter to study what would be the character of such an object in case any such did exist. [Peirce, $C P, 4.447$, c. 1903]

14 Against this one might argue, can a distorted photo of Obama not 'falsely state' that that is how he looks? So this would be a false icon? However, once again, qua picture, a photo just is what it is. To interpret it as saying something false about Obama is: (i) to peg it to a real-world object (thereby rendering it also an index), and (ii) to claim something general about that object's appearance (rendering it also a symbol). 
To sum up then, for icons the relation between representamen and object is closer than for indices and symbols. There is at least a partial identity between them, which is not the case for the other two sign-types:

For a pure icon does not draw any distinction between itself and its object. It represents whatever it may represent, and whatever it is like, it insofar is. It is an affair of suchness only. [Peirce, $C P$, $5.74,1903]$

However we will come to see this partial identity as a source of the icon's unique role and power. I will now outline certain mysteries in necessary reasoning and suggest that the iconic sign holds the key to understanding them.

\section{The Hardness of the Iconic Must}

Lewis Carroll's fable of Achilles and the Tortoise is I believe a brilliant piece of rhetorical phenomenology. ${ }^{15}$ It adroitly highlights both the existence and the puzzlement of a certain feature of our necessary reasoning - a bindingness on our actions (specifically our inferencing) which is acausal. Although this bindingness does not force itself on the reasoner in the way in which a billiard ball makes another ball move, for it is not always adhered to in practice (people do reason invalidly), nevertheless it is in some sense despite this, intriguingly, still binding. We shall see that the bindingness cannot even be explained in a non-question-begging way. Although I have written previously on this topic at some length [Legg, 2008], for current purposes I will cover some of the same ground.

The two mythical racers contemplate Euclid's \#1 geometric proof:

(A) Things that are equal to the same are equal to each other.

(B) The two sides of this Triangle are things that are equal to the same.

(Z) The two sides of this Triangle are equal to each other.

The Tortoise asks Achilles what he would say to someone claiming to accept (A) and (B), but not (Z). Achilles has surprising trouble with this. He devises another conditional to express what he sees as manifestly true and missed by the Tortoise:

(C) If (A) and (B) are true, (Z) must be true.

The Tortoise then asks what difference this inscription makes to what he should do with respect to inferring (Z)), even if he accepts (A) and (B). Achilles resorts to:

15 despite Barry Stroud's somewhat astonishing opinion that, '... there is no sound moral to be drawn from the story about the nature of validity or logical consequence as such' [Stroud, 1979, p. 179]. 
(D) If (A) and (B) and (C) are true, (Z) must be true,

which fails to move the Tortoise to action ... and so on towards infinity, with the impasse never resolved.

It is vital to pay close attention to what is going on here. The dispute is frustrating to Achilles, and he sees the Tortoise as recalcitrant as his slow companion refuses to be bound by a clearly valid argument. One can at this point glimpse an internalism about logic, whose analogy to the metaethical notion is no accident, whereby if one is not motivated to act by logical norms, it seems that one does not fully understand them. ${ }^{16}$ Deep issues about normativity emerge at this point. Yet via his recalcitrance the Tortoise usefully makes the binding process visible, where it normally escapes attention due to its ubiquity.

What is now exposed is a structural isomorphism shared by a sign and an act (of inference). This might seem a curious idea, but how else might we describe what Achilles grasps and the Tortoise does not? We have seen that the disparity between Achilles seeing that he must conclude $(\mathrm{Z})$, given (A) and (B), and the Tortoise not seeing this, cannot be remedied by any further explanatory signs (as conditionals (C), (D), and so on tend to infinity). The fact that further conditional statements are demonstrably useless if the Tortoise does not already understand entailment shows that what is seen by Achilles and not by the Tortoise must be already present, internal to the sign-act pair. The only kind of sign which presents such internal structure is the icon. The epistemic must is therefore an iconic must. However although the foregoing semiotic analysis gives a reason for this claim which consists in eliminating the other two kinds of signs, indices and symbols, from consideration, it is important to note that at the end of the day the strongest, most convincing, argument that icons compel one's reasoning is phenomenological. In essence it is an exhortation of the form: 'Do logic and mathematics, imagine yourself in Achilles' position, and you will see what I mean.'

\section{The Ground of the Hardness of the Iconic Must}

But what is the source of such a widespread and useful compulsion? One of the few contemporary philosophers to face this issue explicitly is Robert Brandom, who writes, '... the most urgent philosophical task is to understand ... the bindingness or validity ... of conceptual norms' [Brandom, 2006, p. 7]. The key, he argues, is a Kantian concept of positive freedom, which by contrast to 'freedom from some kind of constraint', is to be understood as 'freedom to do something' [Brandom, 2006, p. 12, emphasis original]. Such freedom, he argues, relies on two apparently opposing

16 I am grateful to Neil Sinhababu for discussion on this point. 
forces which in fact work together. First one makes individual choices to act. Second one surrenders to norms of ethics which appraise those acts as right or wrong:

... autonomy, binding oneself by a norm, rule, or law, has two components, corresponding to 'autos' and 'nomos'. One must bind oneself, but one must also bind oneself. If not only that one is bound by a certain norm, but also what that norm involves ... is up to the one endorsing it, the notion that ... a distinction has been put in place between what is correct and incorrect according to that norm goes missing. [Brandom, 2006, pp. 12-13]

Together this paradoxical pair results in a 'bonanza' of positive freedom to live in civil society and enter into human relationships. In this regard the realm of logic is entirely analogous. First one makes individual assertions, and second one surrenders to norms of logic which appraise those assertions as consistent or inconsistent (or, in the context of arguments, valid or invalid). Together these result in a 'bonanza of positive expressive freedom' - a freedom to say things which would be impossible without such surrender. In fact Brandom points out that almost every sentence uttered by an adult native speaker is radically novel.

However he then attempts a Hegelian reduction of this Kantian picture, claiming that "what maintains [the norms of logic] is the attitudes of others ...' (p. 16). This appears on the face of it to be a form of conventionalism, and it is not clear that this is what Kant had in mind. For instance Robert Hanna has argued that Kant's account of 'conceptual norms' is, when examined carefully, surprisingly externalist:

... according to Kant the attitude of conviction by its very nature includes a necessary truth: 'objectively necessary holding-to-be-true, which, if it is at the same time subjectively necessary, is conviction' ... So this means that insight both logically requires and is partially constituted by something that is non-subjectively or objectively real (actually realized in space and time) - something given externally to the individual thinker. Put in contemporary terms, and odd as it may initially seem in view of his commitment to idealism, Kant is most definitely an 'externalist' about a priori belief and knowledge. [Hanna, 1998a, p. 117]

From a Peircean perspective such conventionalism cannot be correct, since we have seen that signs whose meaning is established by convention are in fact symbols. Whereas we have established that necessity is signified by the icon. Something is going on in iconic signification that is more enigmatic than conventionalism, something for which a more direct realism seems appropriate, which arguably is why the spectre of platonism 
has hovered over mathematics since Plato. To dispel the spectre we will examine Peirce's existential graphs as a pragmatist technology for coming to understand the reality of the 'iconic must' without reifying it, rather by using it. In a pragmatist spirit we will do this by using the graphs ourselves and observing what happens. In this way I will try to show that one achieves a proper understanding of the iconic must by letting it be what it is - patterns and real relationships both within signs and between signs and acts - rather than, for instance, imagining that signs which signify the 'iconic must' must correspond either to learned patterns of use (i.e., symbols), thereby invoking conventionalism, or to pointers to external objects (i.e., indices), thereby invoking a metaphysical realism. The familiar and oft-relied-upon dichotomy between conventionalism and realism is thereby revealed by Peirce's original triadic account to be false in this case, as it is in many others.

\section{8. 'Diagrammatic Forcing': Peirce's Existential Graphs}

Peirce wrote:

[The] purpose of the System of Existential Graphs ... [is] to afford a method (1) as simple as possible (that is to say, with as small a number of arbitrary conventions as possible), for representing propositions (2) as iconically, or diagrammatically and (3) as analytically as possible. ... [Peirce, $C P, \S 4.561 \mathrm{n}]$

I will here confine myself to the Alpha Graphs which represent propositional logic. ${ }^{17}$ Propositions and connectives are there represented as follows:

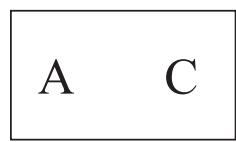

$A \& C$

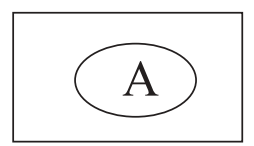

$\sim \mathrm{A}$

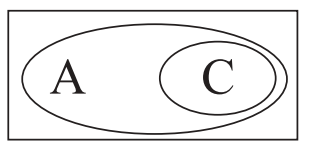

$\mathrm{A} \supset \mathrm{C}$

To illustrate what I shall call diagrammatic forcing in Peirce's graphs, I will present a proof of a tautology derived from Peirce's Law: $(((P \supset P) \supset$ $P) \supset P)$, and compare its invalid close cousin: $((P \supset P) \supset P)$. Here are the rules for the Alpha Graphs in the beautifully elegant presentation of Jay Zeman. Note that by 'odd' and 'even' is meant that a graph is enclosed by an odd or even number of 'cuts' (negations):

17 As is well-known, Peirce also produced Beta Graphs which are equivalent to firstorder predicate logic with identity, and began a number of higher-order and modal systems (known collectively as the Gamma Graphs) which he never finished. 
Proof Rules for Alpha Graphs [Zeman, 2002]

Note that rules with a single arrow are to be read from left to right but a double arrow indicates a rule in each direction, first left to right, second right to left.

0.01 Insertion in odd:
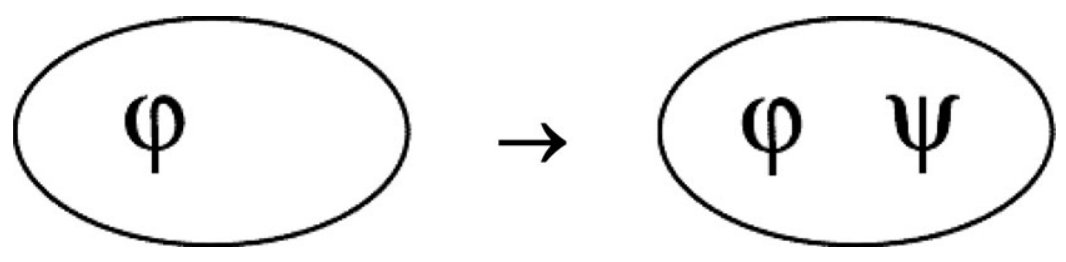

0.02 Erasure in even:
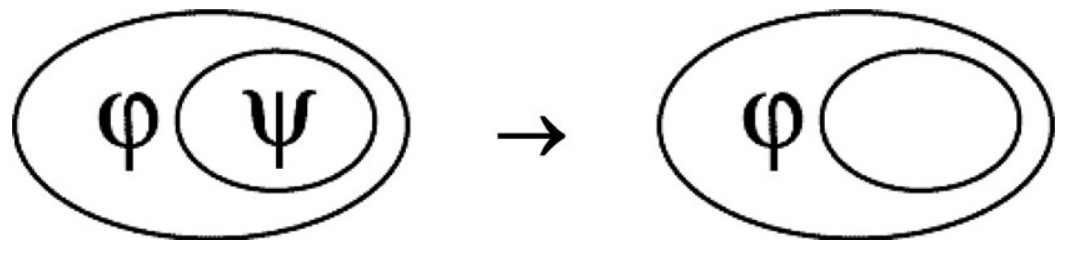

0.03 Interation and 0.04 Deiteration:

(a) In the same area:

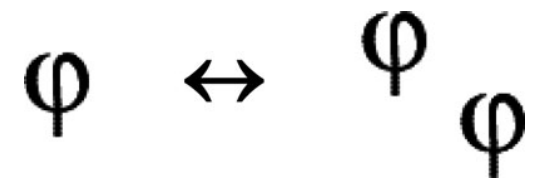

(b) "Crossing Cuts":
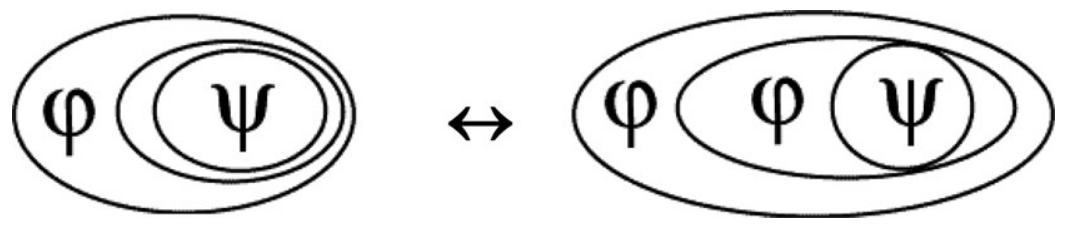

0.05 (adding) and 0.06 (removing) Biclosure:

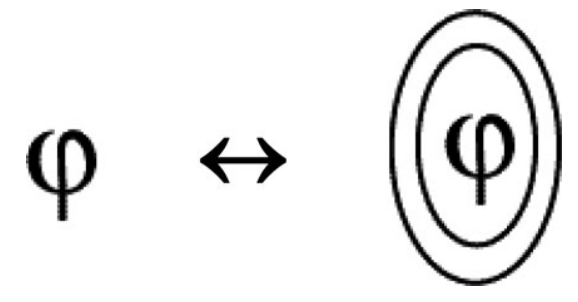


The reader is now invited to follow this proof and observe the diagrams and their own thinking. The first step in the proof of the tautology is to add a double cut, which is permitted anywhere, by 0.05 :

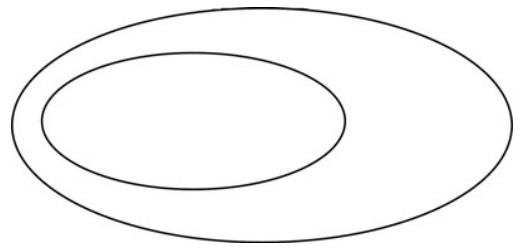

Then an arbitrary graph can be drawn in the first, oddly enclosed cut, by 0.01 :

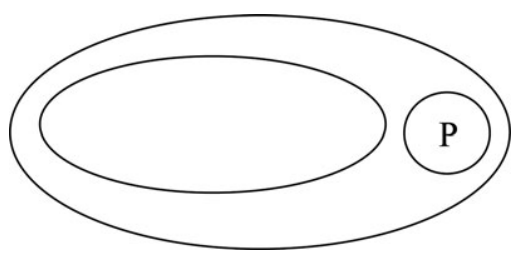

Then this graph can be iterated, one cut inwards, by $0.03 \mathrm{~b}$ :

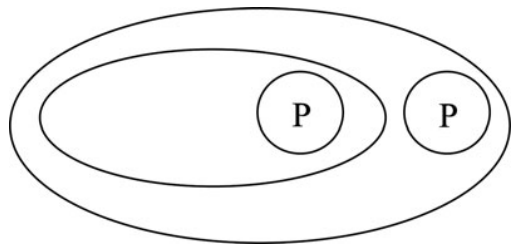

Now another double cut is added, by 0.05 again:

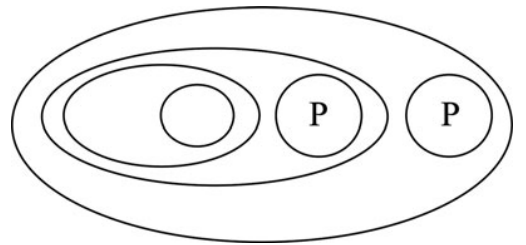

Another new graph is drawn, 3 cuts in, by 0.01 . The last time this rule was used negated $P$ was introduced, while this time the introduced graph consists only of $P$, but rule 0.01 allows the introduction of any graph whatever:

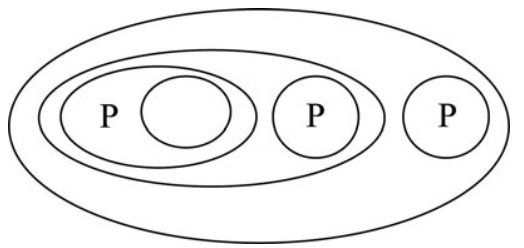


And, for the final result, that graph is in turn iterated, 4 cuts in by $0.03 \mathrm{~b}$ :

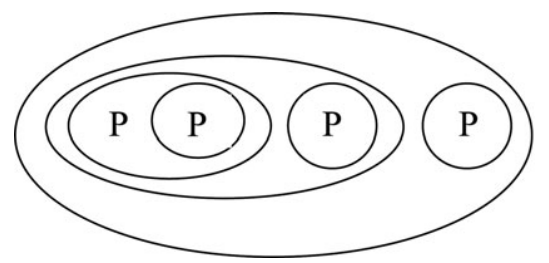

QED.

Let us now compare $((P \supset P) \supset P)$. We begin the same way 0.05 :

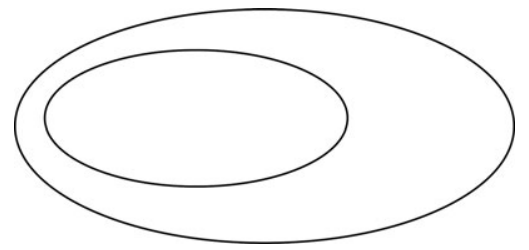

Then use 0.01:

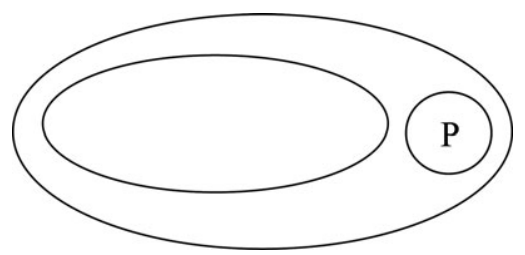

Then 0.03:

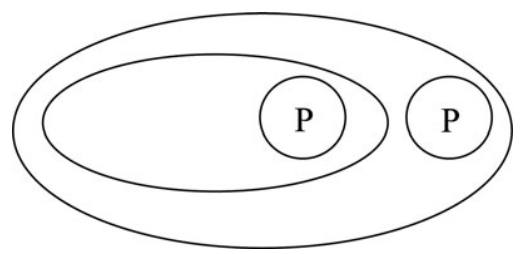

However now we can go no further. What is needed is to establish a $P$ in the second enclosure as follows:

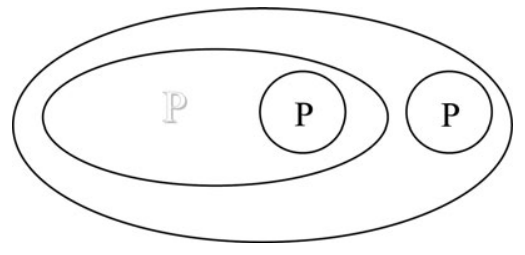

One moral of the story of Achilles and the Tortoise is arguably that a 'logic diagram' includes its rules of use, not just pictures on the page. Upon examining the Existential Graph rules we can see that there is no way to establish a $P$ in the second enclosure. The space is evenly enclosed, 
so (0.01) does not apply. And iteration will not work as the space is less enclosed than that of the $P$ on the left (whereas iterations can only 'cross cuts' in an inward direction). And the $P$ on the right, though also evenly enclosed, is 'sealed off' by the other cut. Somewhat fancifully put, we can see how neither $P$ can 'get out of where it is' to establish $P$ in the middle enclosure. 0.05:

Another example has a particularly attractive feature: $P \vee \neg P$. By

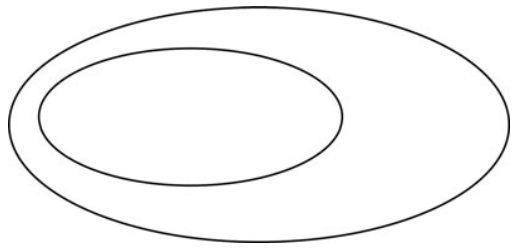

By 0.01:

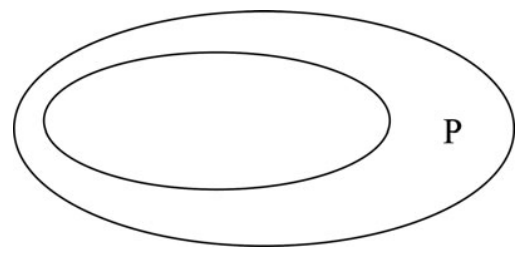

By 0.03b:

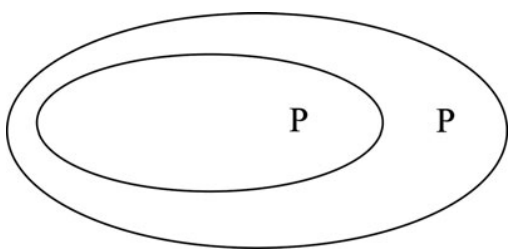

This result has the three interpretations $P \vee \neg P, \neg(P \wedge \neg P)$, and $P \supset P$ simultaneously.

When one aspect of a diagram forces another aspect to be a certain way, it is this that enables us to 'see' necessity. This occurs not by our having epistemic contact with any further 'modal object', but by our fully grasping the relationships amongst the diagram's different parts. Therein lies the answer to Benacerraf, for we saw him criticize mathematics for possessing, 'truth conditions in terms of conditions on objects whose nature, as normally conceived, places them beyond the reach of the better understood means of human cognition', but here no further objects are presupposed.

Of course it is important to note that not all aspects of Peirce's diagrams are forced. One must learn for instance that letters in the Alpha Graphs correspond to propositions, and not to, say, predicate letters applied to an object represented by the larger circle. One must learn that the size with 
which a cut is drawn on the page does not affect its meaning. Those aspects of the diagrams are therefore symbolic. However one cannot force the construction of $((P \supset P) \supset P)$ in the Alpha Graphs on pain of breaking the structure of graphs and rules already present. The more a formalism can force relationships within itself to be the way they are, the more perspicuous the formalism is (in other words, bearing in mind our initial definition of the icon, the more its parts are related in the same way that the objects represented by those parts are themselves related). This forcedness therefore gives us our promised criterion for distinguishing which aspects of a given formalism correspond to necessary truth.

It should be noted that these arguments are not meant to award the Existential Graphs special status with respect to illuminating logical form. Even logic systems such as natural deduction force certain results and forbid others, and are thus irreducibly iconic also. It is just that such logics contain more arbitrary rules which must be learned. Thus the phrase 'symbolic logic' is a bit of a misnomer, insofar as a symbol, at least as understood by Peirce, cannot represent logical form. In Peircean terms the true distinction is not between symbolic and iconic but between algebraic and graphical logics, and the distinction merely concerns how perspicuous the icons are.$^{18}$ In short, the claim is not that Peirce's existential graphs convey unique logical insight, merely particularly efficient insight.

\section{Conclusion}

Necessity is observable. ${ }^{19}$ One just needs to pay attention, not just to individual things but to how those things are related in larger structures. In Peirce's words:

It has long been a puzzle how it could be that, on the one hand, mathematics is purely deductive in its nature, and draws its conclusions apodictically, while on the other hand, it presents as rich and apparently unending a series of surprising discoveries as any observational science. The truth, however, appears to be that all deductive reasoning, even simple syllogism, involves an element of observation; namely, deduction consists in constructing an icon or

18 This explanation is also given in [Legg, 2008, p. 223].

19 It might be argued that, given the point made in the last section that a logic diagram includes its rules of use, not just pictures on the page, and that therefore our understanding of the diagram is irremediably pragmatic, rather than saying that necessity is observable it would be more accurate to say that it is graspable. This is a fine point, but I have elsewhere argued that these are not as different as one might think. Because in working with iconic signs the mind is not passive, but active, and (as Wittgenstein put it) all seeing is 'seeing as', in that sense a seeing is a doing [Legg, 2008, p. 226]. Sincere thanks to Philip Catton for discussions on this. 
diagram the relations of whose parts shall present a complete analogy with those of the parts of the object of reasoning, of experimenting upon this image in the imagination, and of observing the result so as to discover unnoticed and hidden relations among the parts. [Peirce, $C P, \S 3.363]$

In other words, contrary to what Hume suggested, empiricism does not prevent one from 'seeing' necessity. Only logical atomism does. Moreover, in answer to Crispin Wright, we have a 'must-detecting faculty' whose workings are clearly open to view when approached with the right logical tools, and observed in use. Reason is not an inappropriate name for it.

This claim might seem to be in conflict with this paper's call to a greater role for perception in modal epistemology, particularly within the broader context of Peirce's move away from an information-relative (and thus inferential) understanding of modality and towards an ideal-world (and thus experiential) understanding, as sketched in $\$ 3$. Is experience not the opposite of reason? That depends what one means by 'reason'. Contemporary understandings of reason seem to see it as almost coextensive with deductive proof (possibly overly influenced by recent research in artificial intelligence). However an older understanding exists in our philosophical tradition whereby it was precisely the rationalist philosophers who invoked such notions as 'intuition' and 'clear and distinct perception'. Much more needs to be said however to clarify these matters fully.

Along the way careful thought needs to be given to the currently accepted concept of a posteriori necessity, apparently exemplified in 'Water is $\mathrm{H}_{2} \mathrm{O}$ ', and how it might relate to the examples of necessity in mathematics and logic which are the main focus of this paper. In $\$ 3$ the necessary truth of 'Water is $\mathrm{H}_{2} \mathrm{O}$ ' was presented as discovered, as opposed to being discerned a priori. But what is it to discover something? If the hypothesis of this paper is correct then all discernment of necessary truth involves diagrammatic reasoning. It seems possible to give an account of how previously uncognized relationships might be 'discovered' on a diagram, but how this epistemic model might be correlated with what chemists who discerned the chemical formula of water were doing in the lab is less clear. My current suspicion is that, referring back to Peirce's triadic distinction of signs into terms, propositions, and arguments outlined in $\$ 5$, necessity properly understood pertains to the argument (the kind of sign which determines the inferences to be drawn from it). If this is true then insofar as certain propositions are said to be 'necessarily true', this is because they are in fact serving as argument schemas, possibly involving certain other premises which are taken in context to be self-evident. If necessity were to be reconceived in this fashion, the necessity of many current textbook examples would require 
redescription, and it is possible that the necessity of brute identity statements such as 'Water is $\mathrm{H}_{2} \mathrm{O}$ ' would not survive this redescription. ${ }^{20}$ But to address these issues in the fullness they deserve would require another paper.

In the meantime we may conclude that contemporary analytic modal epistemology is wrong to disdain 'imaging' as a guide to modal epistemology. We just need a more general concept of what this might consist in. Interdisciplinary investigation with cognitive science would possibly be illuminating here. Much exciting work in modal epistemology remains to be done along these lines.

\section{REFERENCES}

BenaCerraf, P. [1973]: 'Mathematical truth', Journal of Philosophy 70, 661679.

Blackburn, S. [1984]: Spreading the Word. Oxford: Clarendon Press.

Brandom, R. [1998]: Making It Explicit: Reasoning, Representing, and Discursive Commitment. Cambridge, Mass.: Harvard University Press.

- [2000]: Articulating Reasons: An Introduction to Inferentialism. Cambridge, Mass.: Harvard University Press.

_ [2006]: 'Kantian lessons about mind, meaning and rationality,' Philosophical Topics 34, 1-20.

Brown, J.R. [1999]: Philosophy of Mathematics: An Introduction to the World of Proofs and Pictures. London and New York: Routledge.

Carnap, R. [1947]: Meaning and Necessity. Chicago: University of Chicago Press.

CARroll, L. [1995]: 'What the Tortoise said to Achilles', Mind 104, 691-693.

Chalmers, D. [2002]: 'Does conceivability entail possibility?', in T. Gendler and J. Hawthorne, eds, Conceivability and Possibility, pp. 145-200. Oxford: Oxford University Press.

Giaquinto, M. [2007]: Visual Thinking in Mathematics. Oxford: Oxford University Press.

Hanna, R. [1998a]: 'How do we know necessary truths? Kant's answer', European Journal of Philosophy 6, 115-45.

_ [1998b]: 'A Kantian critique of scientific essentialism', Philosophy and Phenomenological Research 58, 497-528.

HooKWAY, C. [2002]: “ “... a sort of composite photograph”: Pragmatism, idea and schematism', Transactions of the Charles S. Peirce Society 38, 29-45.

_ [2007]: 'Peirce on icons and cognition,' in Conceptual Structures: Knowledge Architectures for Smart Applications, pp. 59-68. Berlin: Springer.

${ }^{20}$ Such a philosophical move would not be without precedent. For instance, Robert Hanna has made the sharply perceptive suggestion that '.. . what essentialists have mislabelled as "necessary a posteriori" propositions all belong to Kant's class of "impure" a priori propositions' [Hanna, 1998a, p. 119]. See also his [1998b] for an extended and subtle Kantian critique of 'scientific' essentialism. 
Houser, N., D. Roberts, and J. Van Evra, eds [1997]: Studies in the Logic of Charles Sanders Peirce. Bloomington: Indiana University Press.

KRIPKE, S. [1959]: 'A completeness theorem in modal logic,' The Journal of Symbolic Logic 24, 1-14.

LANE, R. [2007]: 'Peirce's modal shift: From set theory to pragmaticism', Journal of the History of Philosophy 45, 551-576.

LegG, C. [2003]: 'This is simply what I do', Philosophy and Phenomenological Research 66, 58-80.

_ [2005]: 'The meaning of meaning-fallibilism', Axiomathes 15, 293-318. [2008]: 'The problem of the essential icon', American Philosophical Quarterly 45, 207-232.

LEwIS, D. [1986]: On the Plurality of Worlds. Oxford: Blackwell.

MeYer, J.-J.CH. [2003]: 'Modal epistemic and doxastic logic', in D. Gabbay and F. Guenthner, eds, Handbook of Philosophical Logic, Vol. 10, 2nd ed., pp. 1-38. Dordrecht: Kluwer.

Morgan, C. [1979]: 'Modality, analogy, and ideal experiments according to C.S. Peirce', Synthese 41, 65-83.

Mumma, J. [2009]: 'Proofs, pictures and Euclid', Synthese 175, 255-287.

PeIRCE, B. [1870]: Linear Associative Algebra, Washington, D.C. [lithograph].

Peirce, C.S. [1931-1958]: Collected Papers, C. Hartshorne and P. Weiss, eds. Cambridge, Mass.: Harvard University Press.

- [1992]: Essential Peirce, Vol. 1: Selected Philosophical Writings (18671893). N. Houser and C. Kloesel, eds. Indianapolis: Indiana University Press.

- [1998]: Essential Peirce, Vol. 2: Selected Philosophical Writings (18931913). N. Houser and C. Kloesel, eds. Indianapolis: Indiana University Press.

Pietarinen, A. [2004]: 'Peirce's magic lantern: Moving pictures of thought'. http://www.helsinki.fi/science/commens/papers/magiclantern.pdf.

- [2006]: Signs of Logic: Peircean Themes on the Philosophy of Language, Games, and Communication. Dordrecht: Springer.

Perry, J. [1979]: 'The problem of the essential indexical', Noûs 13, 3-21.

Quine, W.V.O. [1947]: 'The problem of interpreting modal logic', The Journal of Symbolic Logic 12, 43-48.

- [1953]: From a Logical Point of View. Cambridge, Mass.: Harvard University Press.

Roberts, D. [1973]: The Existential Graphs of Charles S. Peirce. The Hague: Mouton.

SHIN, S-J. [1997]: 'Kant's syntheticity revisited by Peirce', Synthese 113, 1-41. [2002]: The Iconic Logic of Peirce's Graphs. Cambridge, Mass.: MIT Press.

Sloman, A. [1968/9]: 'Explaining logical necessity', Proceedings of the Aristotelian Society 69, 33-50.

Stroud, B. [1979]: 'Inference, belief and understanding', Mind 88, 179-196.

Van Inwagen, P. [1998]: 'Modal epistemology', Philosophical Studies 92, 6784.

Wittgenstein, L. [1953]: Philosophical Investigations. G.E.M. Anscombe, trans. Oxford: Basil Blackwell.

Wright, C. [1986]: 'Inventing logical necessity', in J. Butterfield, ed., Language, Mind and Logic, pp. 187-207. Cambridge: Cambridge University Press. 
YabLo, S. [1993]: 'Is conceivability a guide to possibility?', Philosophy and Phenomenological Research 53,1-42.

Zeman, J. [1986]: 'Peirce's philosophy of logic,' Transactions of the Charles S. Peirce Society 22, 1-22.

[2002]: 'Introduction', The Graphical Logic of C.S. Peirce. http://www.clas.ufl.edu/users/jzeman/. 